\title{
Entre la violencia simbólica y la resistencia feminista: el humor como herramienta política ${ }^{1}$
}

\author{
Between symbolic violence and feminist resistance: \\ humor as a political tool
}

Iraide Álvarez Muguruza · iraidealvarezmuguruza@gmail.com

UNIVERSIDAD DEL PAÍS VASCO/EUSKAL HERRIKO UNIBERTSITATEA

Recibido: 02/04/2019

Aceptado: 23/07/2019

\section{Resumen}

El objetivo de este artículo es hacer hablar al humor con la finalidad de identificar quién habla y desde qué posición lo hace persiguiendo, por un lado, desvelar los mecanismos de violencia simbólica ejercidos sobre las mujeres que se hallan ocultos tras las prácticas humorísticas; y por otro, explorar alternativas feministas de resistencia del sistema patriarcal a través del humor. Para ello, a partir de dos casos representativos, y mediante una aproximación bourdiana, se han explorado algunos de los elementos constitutivos de la relación entre la representación de los agentes implicados en el proceso de producción del humor y el mundo social. Los resultados obtenidos presentan la existencia de un habitus patriarcal difundido a través de las prácticas humorísticas así como una tipología de humor feminista que busca estimular el cambio en la dirección de la igualdad y la justicia social.

Palabras clave: feminismo, humor, violencia simbólica, resistencia, agencia.

\section{Abstract}

The main goal of this paper is to get humour talking for the purpose of identify who is speaking and the social position from which the person talks to: on one hand, to reveal the symbolic violence mechanisms exerted against women which are hidden behind humorous practices; on the other hand, to explore feminist alternatives of resistance to the patriarchal system through humour. To this end, from two representative cases, and by means of Bourdieu's theories, some of the constitutive elements of the relationship between the representation of the agents involved in the process of producing humour and the social world have been explored. The results show the existence of a patriarchal habitus widespread by humorous practices as well as a feminist humour typology that seeks to stimulate changes through the direction of equality and social justice.

Keywords: feminism, humour, symbolic violence, resistance, agency.

\footnotetext{
${ }^{1}$ El contenido de este artículo se basa en la reflexión teórica planteada en mi Trabajo Fin de Grado, que es el fruto de una primera aproximación motivada por algunas de las preocupaciones que han marcado mi recorrido académico e ideológico. En este sentido, los conceptos y planteamientos propuestos no configuran un marco interpretativo irrefutable, sino que aspiran a conformar un punto de partida desde el que comenzar a debatir.
} 


\section{INTRODUCCIÓN}

El filósofo Henri Bergson (2008) se interrogaba en su obra La risa. Ensayo sobre la significación de lo cómico cómo es posible que una cuestión tan importante no haya llamado más la atención de quienes hacen filosofía. En este sentido, si bien es cierto que los estudios sobre el humor constituyen un espacio de análisis transdisciplinar, la marginalidad de su interés en el campo particular de los estudios de género es reseñable en la medida en que la relevancia alcanzada por el análisis de las emociones en las investigaciones feministas en las últimas décadas no se ha transformado en una inclinación específica por el humor. Realizar un estudio social que ponga en diálogo ambos campos permite vislumbrar el componente instrumental y performativo del humor que comúnmente se ha minusvalorado en la literatura especializada. En este sentido, el artículo desarrollado en las siguientes páginas se sostiene sobre la siguiente preocupación: ¿qué papel juega el humor en el quehacer feminista?

Partiendo de la base de que toda contribución teórica relacionada con el humor no deja de ser parcial si no se aborda la perspectiva feminista, hemos aspirado a «hacer hablar» a este instrumento con el propósito de identificar quién «habla» y desde qué posición lo hace (Martínez-Palacios, 2018) persiguiendo un doble objetivo. Por un lado, averiguar si la producción de una broma oculta mecanismos de violencia simbólica en función de la posición que ocupa el agente que la produce; y, por otro lado, examinar si es posible visibilizar las opresiones que sufren las mujeres en el sistema patriarcal a través de esta tipología alternativa de humor. De esta manera, se ha enfatizado sobre la relación instrumental del humor con el arsenal de procesos sociales que incorporan poder, y adaptar este engarce al escenario de los estudios de la resistencia feminista.

A este fin, se ha aplicado la teoría bourdiana relativa a la ausencia de capital simbólico y a la dominación en tanto que permite comprender la presencia de agentes que se hallan excluidos del campo cultural que configura toda práctica humorística; pero también la capacidad emancipadora y rupturista con las estructuras que operan opresivamente. ${ }^{2}$ De este modo, la reflexión en torno a la resistencia feminista a partir del fenómeno del humor gira alrededor de la politización de la «diferencia» construida a partir de la posición específica que ocupa cada agente y/o grupo social para, de este modo, conferir legitimidad a las mujeres como agentes activos en el campo social del humor (Young, 1989). El humor se sitúa entonces como «una herramienta que permite relacionar ámbitos de la experiencia cotidiana de la ciudadanía con el plano político, politizando sentimientos» (Casado, 2017: 52) en respuesta a la culpabilización que los dirigentes políticos han arrojado sobre las mujeres de manera individual.

\footnotetext{
2 Se indican en cursiva una serie de nociones que el filósofo y sociólogo francés Pierre Bourdieu acuñó para orientar su marco interpretativo.
} 
No obstante, desactivar las dominaciones implica un cuestionamiento previo de todas aquellas interacciones y prácticas socio-culturales impregnadas en lo cotidiano, ya que se comprenden como relaciones de poder legítimas (Bourdieu, 1988, 1997, 2000, 2008) al basarse en una serie de normas sociales que los miembros de una comunidad conocen y acatan inconscientemente, lo que domina simbólicamente su vida (Garfinkel, 2006) al confluir en la negación de la diferencia en el espacio público (Young, 1990). El humor es, efectivamente, un proceso social reconocido por la sociedad que puede convertirse en un mecanismo de poder que difunde un habitus patriarcal y naturaliza problemas sociales basados en el género, como la cultura de la violación, dando por sentada la posición subalterna que la humanidad ha asignado a las mujeres. De ahí que la exclusión de este campo no sea más que la continuación de la actividad cotidiana de un sistema social sexuado (Bourdieu, 2000).

Con todo, estas normas, generalmente inapreciables, son expuestas a los ojos de la sociedad en el momento en que alguien las infringe mediante una broma. De esta manera, al analizar la risa trascendiendo su superficie, es decir, evaluando su origen y los factores que la configuran, podemos desentrañar la compleja maraña que sumerge en las aguas de la conformidad un acuerdo social que dictamina qué genera risa y qué no en el interior de una sociedad, pero también «su expresión sociocultural, así como las costumbres o las instituciones de la misma» (Jáuregui, 2008 citado en Casado, 2017: 55), lo que nos permite esclarecer la manera en que ésta se percibe no sólo a sí misma sino en relación a los demás (Driessen, 1999). Esta idiosincrasia del humor es de gran utilidad de cara a estudiar aquellos grupos sociales que se ubican en los márgenes donde se localiza la diferencia en la medida en que son permanentemente cuestionados y, por ende, empujados a la auto-reflexión.

Así, al ahondar en el corazón del ejercicio de producción del humor, podemos observar que, además de constituir un fiel reflejo de la realidad social y sus particularidades, «el humor depende de los agentes que lo usan, así como de quienes lo interpretan y del contexto específico donde se produce e interpreta» (Casado, 2017: 56). Lo que muestra la relación jerárquica que se establece a partir de la diferencia entre los distintos grupos sociales de una comunidad concreta; pero también ofrece medios para cuestionar las relaciones de dominación que se extienden a los cuerpos, instituciones y prácticas sociales asumiendo la responsabilidad de enunciar las voces políticas disonantes para lograr que sean visibles en el espacio social.

Es aquí, por tanto, desde donde parte este artículo: de la comprensión de la legitimación de la estructura social (el humor machista) ${ }^{3}$ desde la consideración de la deslegitimación (el humor feminista) como un proceso productivo y generador de resistencias. Por este motivo, la forta-

\footnotetext{
${ }^{3}$ Si bien en el trabajo académico que precede a este artículo utilicé la noción eufemística «humor convencional», en este documento emplearé el concepto «humor machista» puesto que considero que expresa con mayor precisión el planteamiento que subyace a este texto.
} 
leza de este debate sobre la adquisición del «poder para» (Maíz, 2003) subvertir la ausencia de espacios de enunciación (en este caso, en clave de humor) de las mujeres en el espacio público se encuentra en los marcos de análisis que el poder y la resistencia ofrecen para entender y ubicar el mecanismo de dominación masculina que constituye el humor, pero también para intervenir en la interpretación androcéntrica de la realidad política y social.

\section{LA RISA OPRESIVA EN EL CONTEXTO PATRIARCAL DE LO COTIDIANO}

Tomando como referencia la interpretación que Rod Martin (2008) hace de la principal función del humor, la de operar como mecanismo de control orientado a reforzar tanto el statu quo como la jerarquía que los hombres sienten amenazados; y comprendiendo que, de acuerdo con la teoría bourdiana, la organización social no es sino un sistema de relaciones de poder y de creación de sentido entre grupos y clases, cabe comprender que el humor incorpora un elemento violento en la medida en que configura una forma de capital cultural, es decir, un grado de superioridad en la jerarquía social de la sociedad. Pues, pese a que el humor se emplea en los márgenes de «lo no serio» y de «lo inofensivo» (Casado, 2017), esto no implica necesariamente que no busque la efectividad social a través del componente de violencia simbólica.

El punto de partida que nos sirve como paradigma ilustrativo es la broma machista pronunciada en un acto de campaña por Sebastián Piñera, actual presidente de la República de Chile, con el propósito de afianzar su posición en el momento de las elecciones primarias de la organización política 'Chile Vamos'.

Bueno, muchachos. Me acaban de sugerir un juego muy entretenido. Es muy sencillo: todas las mujeres se tiran al suelo y se hacen las muertas, y todos nosotros nos tiramos encima y nos hacemos los vivos. ¿Qué les parece? (El País, 2017)

Algunos datos orientativos que sirven tanto para ilustrar la posición que ocupa quien produce la broma como para comprender cómo participa en el ágora a través del humor los encontramos en la disposición de capitales, pues «el origen social y sus capitales son considerados "cartas del triunfo" en la medida en que garantizan las condiciones materiales de la existencia de una vida privilegiada que equivalen a una buena mano en un juego de póker» (Bullen, 2017: 401). Pero también debemos tener presente que la broma tuvo lugar durante un acto de campaña electoral dirigido al votante potencial, es decir, un público fundamentalmente masculino, lo que nos permite reconocer que en el proceso de producción de la broma entran en juego algunos elementos asociados con la posición, como el sentido y la legitimidad. ${ }^{4}$ Lo que

\footnotetext{
4 Según una encuesta de la Universidad del Desarrollo, Piñera lideraba la intención de voto masculino durante los comicios de 2017.
} 
Entre la violencia simbólica y la resistencia feminista: el humor como herramienta... | Iraide Álvarez Muguruza

hace de las bromas machistas objetos mediadores en las prácticas simbólicas masculinas como un mecanismo social completamente ejecutado por y para la sociedad.

Una de las características más significativas del ejercicio de todo actor político, en contextos de comicios electorales, es la asignación de sentido a las formas de comunicar en función de las ganancias que se pueden obtener. Los beneficios electorales de la producción de una broma de tal dimensión, como por ejemplo la ampliación de la popularidad de Piñera a través de la afirmación del yo (Bergson, 2008), hallaron su traducción material en el aumento de votos a su favor durante los comicios. Así, se deduce que la reproducción de un habitus lingüístico legitimado por el agente dominante de la modernidad ante su mismo público, que reconoce las reglas lingüísticas, favorece la evaluación positiva del candidato. $^{5}$

Por otro lado, en el momento en que se enmarca la producción de esta broma se produjo un repunte en la tasa de violencia de género en la región Chile respecto al año inmediatamente anterior. ${ }^{6}$ En este sentido, la risa, entendida como catalizador del acontecer histórico de una sociedad, da cuenta de la realidad social dominante en la región durante el espacio de tiempo descrito, lo que nos permite valorar si esta variable influye en la legitimación de una tipología de humor que provoca la carcajada a través de la humillación verbal y, por lo tanto, simbólica del colectivo que conforman las mujeres, y que sostiene el pilar de la representación social del machismo.

En el año 2011, durante una cumbre en México, Piñera protagonizó la realización de una broma de temática similar. ${ }^{7}$ El hecho de que tales declaraciones no sean una circunstancia puntual, sino una tópica común en los discursos públicos del presidente de Chile, encubre dos significaciones anejos: por un lado, se ha consolidado la legitimidad del modelo de masculinidad hegemónica al que los votantes buscan acercarse; ${ }^{8} \mathrm{y}$, por el otro, la producción de una serie de intercambios simbólicos entre Piñera y sus potenciales electores por medio de mensajes fáciles de reconocer, consumir y transmitir — las bromas- han intensificado la reproducción de la estructura patriarcal en la formación política "Chile Vamos». ${ }^{9}$ Además, el político chileno posee el suficiente capital simbólico como para transmitir sus bromas machistas sin poner en juego ninguna de sus disposiciones.

\footnotetext{
${ }^{5}$ Es claro que Piñera aumentó su respetabilidad y dio una nueva dimensión, más humorística, a su labor y a la política en general; y al mismo tiempo mostró que lo más importante en el humor político, esto es, en el humor y en la política, consiste en ser el sujeto creador y marcar la agenda.

${ }^{6}$ Según datos proporcionados por el Instituto Nacional de Estadísticas de Chile.

${ }^{7}$ El político, en una tentativa por ilustrar en tono jocoso la diferencia entre una mujer y un político, expresó: "Cuando el político dice que "sí" quiere decir "tal vez", cuando dice "tal vez" quiere decir que "no" y cuando dice que "no", no es político. Cuando una dama dice que "no" quiere decir "tal vez", cuando dice "tal vez" quiere decir que "sí", cuando dice que "sí" no es dama" (BBC Mundo, 2017).

${ }^{8}$ La biografía personal del político, publicada en el sitio web oficial del Gobierno de Chile durante el período 2010-2014, refleja la representación de Piñera como ese modelo social hegemónico que impone un modo particular de configuración de la posición de los hombres. Un ejemplo ilustrativo es el título «El hombre de familia» de una de las secciones en que se divide la página web.

${ }^{9}$ Una muestra de ello es el equipo de gobierno de Piñera, dominado por hombres.
} 
En el diseño del edificio conceptual que se halla tras este proceso de interpretación del humor machista se aprecia, por tanto, una correlación entre componentes sociales y culturales del campo y el habitus de Sebastián Piñera que fortalece las disposiciones que, producto de su biografía, acarrea consigo. De esta manera, observamos que cuando una expresión cultural tal que el humor entra en juego con la significación de rasgos sociales y culturales que se integran en las disposiciones de un agente masculino, como el liderazgo, el poder (político, económico y/o social), el reconocimiento e incluso la libertad sexual, esta forma de expresarse resulta más compatible con el habitus.

Desde esta perspectiva, el humor machista «pide ser visto como una construcción política elaborada con una finalidad politizadora» (Moreno, 2007). En concreto, la de generar ambientes risible cimentados sobre la concepción de las mujeres como un blanco objeto de la burla. De esta manera, una relación social aparentemente tan cercana como la que une a un actor político con su potencial electorado, aquel que es de su mismo sexo, puede mantenerse a través del ejercicio de la violencia simbólica sobre las mujeres, de quienes las encuestas revelaban que se inclinaban electoralmente hacia la candidata Beatriz Sánchez, ${ }^{10}$ a través de la complicidad de los potenciales electores de Piñera. Una complicidad que radica en el intercambio de apoyos, ya que al satisfacer Piñera sus propios intereses, complació también los del grupo masculino, pues la posición del político dentro del campo equivale a la posición que ocupa el grupo dominante, que es el representado en el espacio social.

Los planteamientos expuestos llevan a interpretar el humor como un bien social y cultural convertido en capital simbólico de las posiciones dominantes para reproducir su posición en el espacio social en la medida en que cuando «las formas cómicas adquieren un carácter no oficial, su sentido se modifica para transformarse finalmente en las formas fundamentales de expresión de la cosmovisión y la cultura populares» (Bajtín, 1971: 12); y a entender que la broma tiene un sexo. Es más, el humor nos permite, junto con otros elementos, identificar la posición de los sujetos en base al uso y consumo que hacen de él.

Tomando como punto de partida los puntos anteriores, nos centraremos en dos cuestiones de interés. En primer lugar, podemos afirmar que en el humor machista la risa se produce desde la posición del agente privilegiado en tanto que el presidente de Chile es simbólicamente más poderoso que la persona sobre la que recae su broma. Por otro lado, la risa de los hombres, los agentes que gozan del poder en la estructura del sistema patriarcal, revela una actitud de humillación al ser capaces de auto-identificarse en los significados construidos en las bromas, mientras que las mujeres, que juegan el papel de subalternas, no. En pocas palabras, el humor es beneficioso, sí, pero no para todas las personas.

Así, encontramos que existe una interconexión entre ambos aspectos en la medida en que, en conjunto, promueven «la capacidad de predisponer a un conjunto de sujetos (hombres)

${ }_{10}$ Así lo indica el perfil de votante de cada uno de los candidatos a la presidencia chilena elaborado por DecideChile. 
a asumir como natural la validez de una asociación establecida entre una serie de elementos categorizados, en este caso, el orden patriarcal» (Fernández, 1986 citado en Álvarez, 2018: 22). De esta manera, las bromas que invitan al público a tomarse como un asunto risible el abuso sexual hacia las mujeres respaldan, sustentan y normalizan a través de una forma latente del lenguaje la denominada cultura de la violación.

En este sentido, el humor machista tiene una función social en los escenarios de dominación: propagar un habitus instituido por las formas patriarcales de poder. Así, podemos determinar como causa, pero también como consecuencia de las relaciones de poder, la legitimidad que mantiene la dominación que encarnada por las mujeres: la violencia simbólica. Por un lado, como herramienta con capacidad de reproducción y uniformización de los marcos de percepción; pero al mismo tiempo como asegurador de la dominación en las relaciones sociales, en la medida en que goza del potencial de racionalización. Como vemos, aquellos que producen las bromas machistas asumen cierto conocimiento sobre las mujeres, tanto de manera individual como colectiva, y las ajusta a las fórmulas estereotípicas y normalizantes básicas para hacer de ellas un objeto risible. ${ }^{11}$

Debido a que el «arma oculta» (Harvey, 1999) en la risa cultivada por y para los hombres no es considerada un caso violento de opresión, la dominación ejercida es aún más difícil de advertir, pero también de combatir. Sin embargo, no podemos dejar de considerar la importancia del humor como una manifestación y acto de carácter social que no puede separarse de la dinámica de poder asimétrica de la interacción endogrupal (hombres) / exogrupal (mujeres) que opera a través de constantes recordatorios de la pertenencia de estas últimas a un grupo social considerado inferior, lo que permite perpetuar aquellos estereotipos construidos por el patriarcado que denigran e invisibilizan. En definitiva, el humor reproduce esquemas mentales establecidos por la cultura hegemónica patriarcal, lo que da continuidad tanto al sistema como a la dominación masculina. ${ }^{12}$

\section{ENFRENTAR HUMORÍSTICAMENTE EXPERIENCIAS OPRESIVAS COMO PROCESO DE TRANSFORMACIÓN FEMINISTA}

Lo planteado hasta ahora nos conduce a la preocupación expresada inicialmente relativa tanto a la dominación como a la necesidad de proponer acciones alternativas de resistencia, planteando el papel del humor como una herramienta orientada a la visibilización

\footnotetext{
11 El humor machista asume y reproduce de este modo que todas las mujeres son naturalmente menos inteligentes que los hombres, que fueron creadas para trabajar en el hogar y que desean los roles que las normas sociales les han asignado y definido como tal.

12 Un ejemplo paradigmático de lo que trato de ilustrar lo encontramos en las extendidas «bromas de suegras» (en contraste, no hay bromas de suegros). Estas bromas perpetúan los estereotipos negativos u opresivos, uno de los pilares de la cultura patriarcal, al ser políticamente efectivos para mantener el dominio de los hombres sobre las mujeres.
} 
pero también a la subversión de la opresión ejercida mediante las bromas a través de la toma de conciencia. Es precisamente la potencialidad metafórica del humor lo que desencadena un código desde el que poder analizar la situación social con un adecuado distanciamiento cognitivo pero también emocional de su situación opresiva para así observar que ésta existe y reconocer quién es responsable de mantenerla; y, a la vez, la posibilidad de ser escuchadas.

Desde este marco de la resistencia podemos entender la conexión entre la agencia y las estructuras sociales con la vocación de cambio «de abajo hacia arriba» (Vasallo, 2015) con la que surge este concepto, provisto de un carácter visiblemente innovador, ingenioso e imaginativo (De la Fuente, 2013: 200). Por tanto, la capacidad de subvertir el humor machista abarca la adquisición del poder para, de este modo, obtener capacidad crítica, autónoma $\mathrm{y}$, en consecuencia, rupturista con los sistemas de significados humorísticos hegemónicos que sostienen las relaciones de poder; posibilitando el resignificar conceptos e imágenes (Scott, 2003). Precisamente mirando a este horizonte se analiza el humor feminista como un proceso de articulación de cambio emprendido por las mujeres.

En este sentido, la estrategia humorística desarrollada por las mujeres ataca precisamente al sentido universal de verdad construido por los hombres, y ofrece una nueva visión trascendiendo de manera creativa (sin negar o teatralizar) la seriedad emocional que incorporan temas que tienen lugar en el interior de un marco opresivo concreto (el patriarcado) con la finalidad de modificar tanto la actitud como la perspectiva unidimensional que el colectivo masculino proyecta sobre las mujeres, proponiendo una representación más precisa y completa de ellas que busca alejarse de cualquier percepción indiferenciada de un individuo respecto a todos los miembros de ese mismo grupo social.

Un ejemplo paradigmático lo encontramos en la campaña viral emprendida en Turquía en el año 2014 por miles de mujeres como expresión y reacción a las declaraciones públicas de Bülent Arinç, el entonces viceprimer ministro. Las palabras del ex viceprimer ministro turco merecen ser reproducidas parcialmente por ajustarse a lo que tratamos de ilustrar en este artículo:

El decoro es un ornamento de la mujer (...). La mujer debe ser decorosa, saber qué es lo decente. No debería reírse en voz alta delante de todo el mundo, ni hacer movimientos seductores. (...) ¿Dónde están nuestras chicas, que se sonrojaban, bajaban la cabeza y miraban hacia otro lado cuando nosotros las miramos a la cara? (The Guardian, 2014) $)^{13}$

Frente a esta arenga, que señalaba a las mujeres como culpables de la destrucción de la sociedad y los valores familiares turcos, éstas respondieron con humor difundiendo por las

${ }^{13}$ Tras la victoria del AKP, partido político islamodemócrata, en las elecciones generales de 2011 los sectores conservadores del islam se obstinaron en injerir en los estilos de vida de la ciudadanía el menoscabo de las libertades ciudadanas (Rodríguez, 2014) y, en particular, en torno a la figura de la mujer. 
redes sociales fotografías suyas en las que se mostraban en actitud de manifiesta risa bajo los hashtags \#kahkaha («risa» en turco), \#direnkahkaha («la risa es la resistencia») y \#direnkadin («resisten las mujeres»). ${ }^{14}$

Entonces, ¿qué diferencias encontramos respecto al humor machista? Lo primero que observamos es que la risa ni es producto ni brota de un agente privilegiado, sino que se trata de una estrategia y acción política desarrollada por las subalternas como respuesta al «espíritu de seriedad» (Sartre, 2016) encarnado en Bulent Arinç, quienes perseguían el objetivo de desafiar las abstracciones estáticas de la universalización de un sistema de pensamiento sometido a las leyes patriarcales. Es decir, el humor feminista surge en contextos de seriedad y reacciona de manera humorística como herramienta de resistencia frente a las proyecciones que el patriarcado coloca sobre las mujeres.

De manera secundaria, la colectivización del mensaje nos indica que una de las señas identitarias de esta tipología de humor construida por las subalternas cuenta el valor colectivo de la exposición en el ágora, la politización de los estereotipos patriarcales y el empleo de un lenguaje simbólico «desterritorializado». El hecho de que las mujeres turcas aprovecharan la grieta que considera al humor como una herramienta de comunicación artística es un elemento que favoreció a la viralización de la campaña en la encarnación de una resistencia de carácter pacífico, pero también reflejó la necesidad de los medios colectivos para declarar su legitimidad. No obstante, el humor en el caso estudiado no constituye una estrategia premeditada de acción política sino que surgió en el devenir del acto reivindicativo con la espontaneidad con la que éste se desarrolló.

En tercer lugar, retomando la noción del humor y la risa como un ejercicio del poder, se puede realizar una doble lectura del alcance de ambos elementos como instrumentos políticos, pues permiten fundar pero también vencer el miedo. No parece aventurado afirmar que:

«la represión de la risa constituye un poderoso mecanismo de control orientado a evitar cualquier práctica humorística producida por mujeres en la medida en que éstas contienen un ingrediente de amenaza contra las instituciones políticas y religiosas y, por tanto, contra la jerarquía social que mantiene en un estado de subordinación a las mujeres». (Álvarez, 2018: 28)

De esta reflexión se deriva que la risa es un mecanismo congruente de resistencia en la medida en que se presenta desde la subalternidad revelando una lucha por el cambio de mentalidad, tratando de superar -cuestionándola- a una autoridad que va perdiendo su ra-

\footnotetext{
${ }^{14}$ De manera simultánea, germinaron a lo largo del norte de África y Oriente Medio una oleada de manifestaciones populares bautizadas como «Primavera Árabe» que contribuyeron a la "construcción de una cultura política de resistencia feminista» (Strzelecka, 2017) en los países de mayoría musulmana, lo que permitió a las mujeres turcas encarar al poder patriarcal para renegociar su posición en la sociedad. Por este motivo entendemos que el binomio humor-mujeres va ligado a las circunstancias culturales y sociales del género, y ha de entenderse como una forma de franquear barreras y conquistar un espacio que, discursivamente, les ha estado negado (Merino, 2001).
} 
zón, su sentido y capacidad de dar una solución a las demandas de las mujeres. Por este motivo es necesario que las propias mujeres subalternizadas repoliticen las bromas que se producen y tienen impacto sobre ellas, resignificando sus contenidos y gestionando esta herramienta alternativa de estrategia discursiva para así conseguir transmitir una imagen social más positiva del colectivo femenino.

Como demuestra la literatura, en las sociedades patriarcales los roles sociales que se le asignan a cada sujeto están claramente definidos en función del sexo. La imposición de un modelo de comportamiento considerado aceptable por la moral religiosa, es decir, aquel pasivo y decoroso, no es más que una estrategia legitimada por el sistema sexo-género orientada a mantener el dominio sobre las mujeres a través de su confinamiento en la esfera privada. Estas normas sociales también impedían las expresiones físicas de dimensiones extravertidas provocadas por el humor, de modo que la espontaneidad en cuanto a la urbanidad ha encorsetado la conducta de las mujeres según éstas eran socializadas y educadas, bajo la atenta mirada de un entorno que condena la ruptura del orden hegemónico (Campan, 1845; Anderson y Zinsser, 2007).

Es por ello que las manifestaciones ruidosas de la producción humorística, al ser consideradas subversivas y transgresoras de las normas socialmente establecidas, han promovido en la actualidad «la aparición de un sujeto social que surge como una biolegitimidad reformulada y empoderada» (Casado, 2017: 66) a través de un discurso que exigió que las mujeres turcas se carcajearan de la prohibición de reírse en el espacio público, es decir, que tuvieran más presencia y poder político. El carácter desafiante del humor feminista proporciona, por tanto, una gran capacidad pedagógica como transmisor de nuevas representaciones sociales resistiendo a los discursos ideológicos dominantes, exponiendo al absurdo sus contradicciones para reírse de ellas.

En el ámbito del humor, esta actitud desafiante fomenta la apertura epistémica a múltiples perspectivas, uno de los primeros pasos en el reconocimiento de la opresión, lo que expone y permite deconstruir los significados y la seriedad establecida en torno a la realidad patriarcal. Y no lo hace dando respuesta a los métodos ofensivos del humor machista, sino gozando de la capacidad de desenmascarar el sexismo sistemático mediante su exposición al absurdo. El distanciamiento lúdico desde la posición enunciativa actúa de este modo como un contradiscurso feminista que critica las representaciones sociales de las mujeres que el orden patriarcal ha normalizado, pero también como un superdiscurso (Méndez, 2013, 2014) que propone una nueva representación social compartida por su carácter testimonial.

El humor feminista persigue tanto la autoafirmación individual como la solidaridad grupal, basándose en la construcción intersubjetiva de espacios mentales que la audiencia necesita para comprender su situación de discriminación en la vida cotidiana y en la risa conjunta que genera la ridiculización de estereotipos lo que, en base a un principio de representatividad, crea una identificación colectiva y visibiliza cuestiones ignoradas por ser 
características de las mujeres o por pertenecer a la microcultura de una sociedad. Así, las mujeres turcas, tomando un asunto serio, ${ }^{15}$ aspiraron a una transformación en positivo de su situación en una sociedad patriarcal empleando como estrategia de acción la herramienta política del humor para revelar las incoherencias del orden sociopolítico que las subyuga con la aspiración de que la risa que procede de la acción humorística lograse su objetivo crítico y concientizador. ${ }^{16}$

Descubriendo esta cortina de humo podemos observar que, con esta acción, aquellas que habían sido subalternizadas por el político no se limitaron a reír con actitud estoica ante una realidad injusta que es inexorable sin importar lo que hagan. Por el contrario, se rieron de las incoherencias existentes entre la forma en que está socialmente construida la realidad social y la manera en que consideraban que debería construirse, muy lejos de estar contentas con su aceptación. A través de este ejemplo podemos destacar las posibilidades del humor como un instrumento útil para la resistencia feminista que ha hecho posible la ocupación de nuevos espacios y aspira, en consecuencia, al cambio social empleando como fórmula la exposición satírica de las incoherencias del sistema patriarcal.

Desde esta perspectiva, la necesidad de tomar conciencia feminista en situaciones cotidianas es cardinal, pero una detección prematura del machismo es aún más importante cuando el detonante de la risa son estereotipos perjudiciales. Así, y dado que quienes están oprimidas por el sistema político en que se hallan inmersas se ubican en los márgenes de la sociedad, el humor feminista permite navegar a través de la ambigüedad y modificar los márgenes en relación con el centro, lo que ofrece a las subalternas un privilegio epistémico del que no gozan aquellos con poder y privilegios sociales, revelando de esta manera que su situación no es impermeable al cambio.

\section{LA PRODUCCIÓN HUMORÍSTICA DESDE EL MARCO DE LA POSICIÓN SOCIAL DEL AGENTE}

A través de la producción humorística podemos comprender los elementos incorporados en el habitus, campo y capital como la traducción de la necesidad que tienen algunos hombres de revalidar su masculinidad como algo (con)natural a las disposiciones incorporadas en su grupo de origen; pero también como un obstáculo para las mujeres en su acceso, haciendo de la producción de humor algo difícil - pero no imposible- de alcanzar ya que los requerimientos para hacer del humor algo propio superan sus posibilidades, entendidas desde la perspectiva del capital y las disposiciones prácticas.

\footnotetext{
${ }^{15}$ La acepción de «seriedad» en este párrafo se atiene a la habitual concepción que comprende de forma estrictamente binaria y opositiva la seriedad vs. el humor.

${ }^{16}$ Muestra de ello es el encumbramiento de la lista de trending topics en la red social Twitter, así como la suma internacional de mujeres a la reivindicación turca.
} 
No obstante, el habitus y el capital simbólico no son un destino. Como se muestra en el Cuadro 1, el humor entendido desde sus dos interpretaciones (legitimadora/deslegitimadora de las estructuras sociales) permite que se desarrolle una pugna por el aumento del poder de cada uno de los grupos sociales en función de los intereses y las estrategias desarrolladas para alcanzarlo.

\section{Cuadro 1}

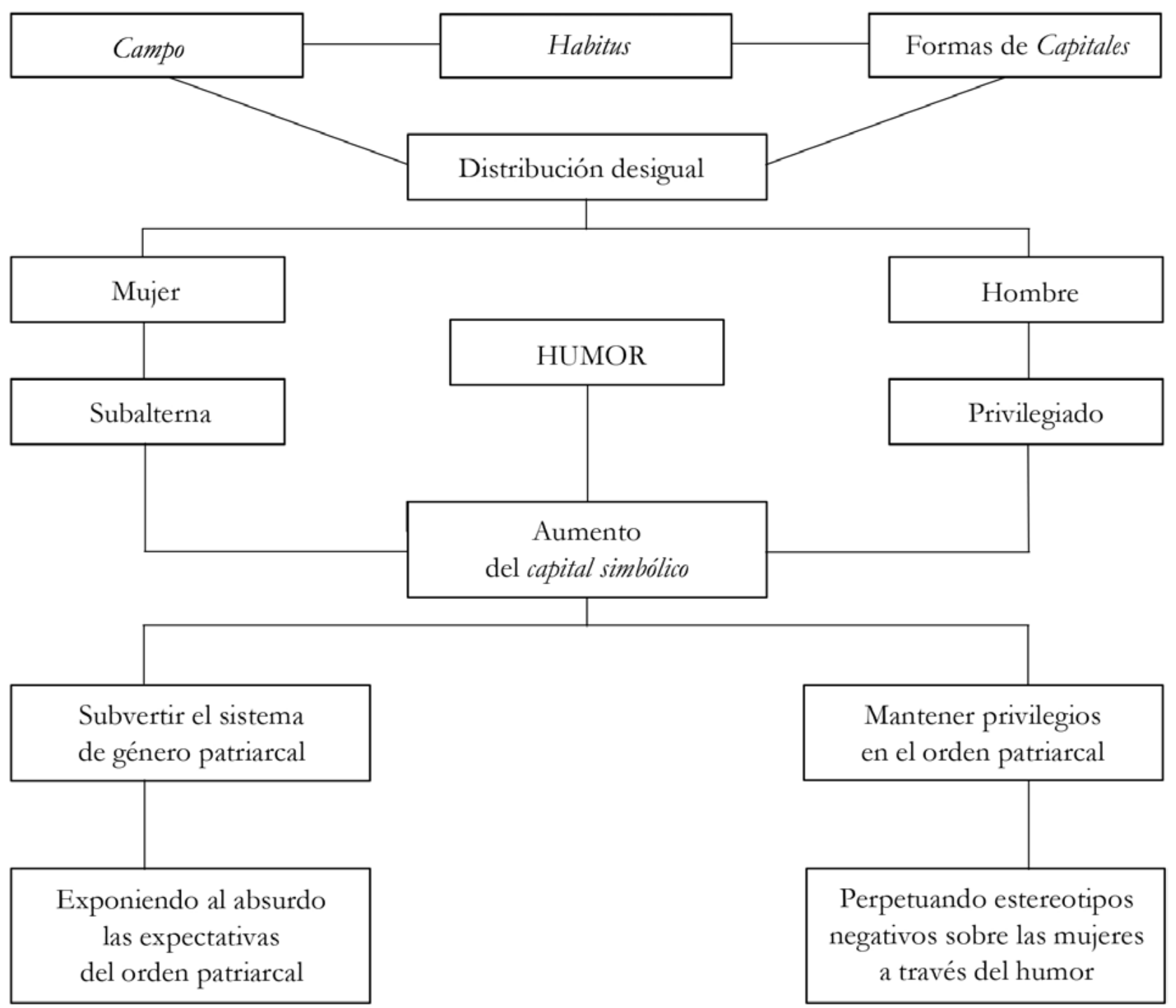

Fuente: Álvarez, Iraide (2018). Otras risas son posibles. El humor: una herramienta política de resistencia feminista (p. 29). Leioa: UPV/EHU.

Así, podemos afirmar que el humor feminista obedece a las transformaciones cognitivas así como al replanteamiento de las reglas sociales. Pero, a diferencia del humor machista, que busca la risa caricaturizando a la diferencia, implica una reevaluación de las propias reglas heurísticamente preidentificadas. Además, la modificación de los marcos de referencias no es un imperativo, sino que simplemente anima a formar parte de la producción de la alegría. Un sentimiento que, en el humor feminista, desempeña el pa- 
pel de preparar las emociones apropiadas para motivar al público a localizar una inconsistencia enmascarada para, a partir de ahí, tomar conciencia sobre la opresión sistemática que sufren.

El humor, por tanto, es un arma de doble filo: proporciona un medio legítimo para perpetuar la autoridad y, simultáneamente, alienta a desafiar las estructuras de poder mediante la producción humorística por parte de las mujeres, quienes, al invertir situaciones sociales convencionales al ponerse en primer plano, amenazan las normas de género más básicas. Una mujer ingeniosa desvirtúa la posición social, ya que «ese ingenio demuestra seguridad en sí misma» (Walker, 1991: 22), lo que viola las normas de socialización prescritas para las agentes subalternas y propone un nuevo rol para ellas. Las mujeres que se encuentran en las prácticas humorísticas un espacio de enunciación y lo hacen suyo, rompen brechas al representar escenas cuyos paisajes desafían las convenciones sociales, logrando desprenderse de los estereotipos para percibir a ambos sexos como divertidos.

\section{CONCLUSIONES}

Con todo lo dicho, podemos concluir afirmando que la conversión del humor en un capital simbólico es el libro de claves para reconocer que los hombres gozan de una posición de privilegio en la medida en que gozan del suficiente capital simbólico para reproducir las prácticas humorísticas en una dirección top-dowm y mantenerse en el poder. Las expresiones machistas del humor pueden traer consigo la aceptación y encarnación de los discursos hegemónicos que hacen posible la dominación de parte de la propia sociedad al reproducir esquemas mentales instaurados por la cultura patriarcal, concibiendo de esta manera una situación de violencia simbólica que da continuidad al sistema y a la dominación masculina. En este sentido, y dado que toda broma se convierte en un mensaje fácil de transmitir y de consumir, esta herramienta supone uno de los medios más eficaces de apropiación de discursos normativos que se inoculan en la mente de las personas de manera imperceptible, por lo que no son conscientes de que están adquiriendo o reaprendiendo estos conocimientos.

Entonces ¿cuáles son las opciones de aquellas que no están satisfechas con el orden sociopolítico humorizado que les ha tocado vivir? Una vez exploradas las posibilidades de resistencia feminista a esta dominación a través del espíritu crítico y creativo de la risa de las mujeres, podemos decir que se reducen esencialmente a una: la intensificación incremental del potencial subversivo, los espacios y las prácticas de humorización en clave feminista más allá de los actualmente existentes con los objetivos de desafiar y quebrantar la legitimidad humorística que sostiene las relaciones de poder y de acceder a nuevos espacios de enunciación que hagan posible la visibilización de las mujeres al margen de los discursos hegemónicos mediante la crítica en tono humorístico de las opresiones patriarcales sufridas por las mujeres en su vida cotidiana, con la intención declarada de transformar las formas de pensar y de sentir modeladas por la cultura patriarcal. 
Todo ello ha permitido descubrir que el humor feminista sirve, por un lado, para visibilizar algunas de las opresiones que sufren las mujeres en el sistema de dominación masculino a través de su exposición social y la deconstrucción de la objetivación femenina; por otro, para generar sublevaciones simbólicas que desafían el mapa cognitivo que traza una geografía simbólica que es estática y jerárquica como corolario de las genealogías masculinas. De ahí que digamos que el humor y la risa también son herramientas de las que puede valerse la resistencia para hacer frente a los discursos de dominación, pues contienen el componente crítico propio de los agentes del cambio social y gozan del potencial necesario para lograr que las mujeres se identifiquen colectivamente en la iniciativa de crear/cocrear otros imaginarios riendo y haciendo reír de manera alternativa.

En el sentido apuntado, el desarrollo de esta aproximación teórica invita a seguir indagando en esta dirección, que apunta a la necesidad de una repolitización de la vida mediante una nueva ética en la que el humor machista cedería terreno a una modalidad humorística feminista para representar democráticamente a la polis.

\section{REFERENCIAS BIBLIOGRÁFICAS}

Álvarez, Iraide (2018). Otras risas son posibles. El humor: una herramienta política de resistencia feminista. Trabajo Fin de Grado. Leioa: Universidad del País Vasco/Euskal Herriko Unibertsitatea.

Anderson, Bonnie S. y Zinsser, Judith P. (2007). Historia de las mujeres. Una historia propia. Barcelona: Crítica.

Bajtín, Mijail (1971). La cultura popular en la Edad Media y el Renacimiento. Barcelona: Barral Editores.

Bergson, Henri (2008). La risa. Ensayo sobre la significación de lo cómico. Madrid: Alianza.

Bourdieu, Pierre (1986). The Forms of Capital. En Richardson, John G. (ed.) Handbook of theory and and research for the sociology of education (pp. 241-258). Nueva York: Greenwood Press.

—, (1988). La distinción. Madrid: Taurus.

—, (1991a). El Sentido Práctico. Madrid: Taurus Ediciones.

—, (1991b). Language and Symbolic Power. Cambridge: Polity Press.

—, (1995). Las reglas del arte. En Martínez-Palacios, Jone (coord.), Participar desde los feminismos. Ausencias, expulsiones y resistencias (p. 520). Barcelona: Anagrama. 
—, (1997). Razones prácticas. Sobre la teoría de la acción. Barcelona: Anagrama.

—, (2000). La dominación masculina. Barcelona: Anagrama.

Bullen, Aída A. (2017). Agentes, capitales y campo de la política de educación ambiental en Michoacán. Revista Mexicana de Investigación Educativa, vol. 22 (73), pp. 399-420.

Campan, Jeanne L. H. (1845). Tratado de educación de las niñas, o sea, consejos a las madres que desean educar bien a sus hijas; seguidos de varios preceptos de moral y de urbanidad para la instrucción de las muchachas de condición humilde. Barcelona: Imprenta de D. Manuel Saurí.

Casado, María Isabel (2017). El Humor desde las Ciencias Sociales. El humor como herramienta de resistencia en movimientos sociales. El caso del 15M. Perifèria, vol. 22 (1), pp. 51-74. DOI: http://dx.doi.org/10.5565/rev/periferia.513

Checho Hirane: «El chiste que contó el presidente Piñera es mío» (21 de junio de 2017). ADN Radio. Disponible en: http://www.adnradio.cl/noticias/sociedad/checho-hiraneel-chiste-que-conto-elpresidente-pinera-es-mio/20170621/nota/3499703.aspx

De La Fuente, María (2013). Poder y feminismo: Elementos para una teoría política. Tesis Doctoral. Barcelona: Universitat Autònoma de Barcelona.

DecideChile (2017). 1. ${ }^{\mathrm{a}}$ vuelta y parlamentarias. Disponible en: https://www.decidechile. cl/\#/ev/2017/primeravuelta

Driessen, Henk (1999). Humor, risa y trabajo de campo: apuntes desde la antropología. Una historia cultural del humor. Madrid: Sequitur.

Fernández, James W. (1986). Some Reflections on Looking into Mirrors. En Fernández, James W. Persuasions and Performances. The Play of Tropes in Culture (pp. 157-171). Bloomington: Indiana University Press.

Garfinkel, Harold (2006). Estudios en Etnometodología. Anthropos: Madrid.

Guha, Ranajit (1988). On Some Aspects of the Historiography of Colonial India. En Guha, Ranajit y Spivak, Gayatri (eds.) Selected Subaltern Studies (pp. 1-7). Oxford: Oxford University Press.

Harvey, Jean (1999). Civilized Oppression. Lanham: Rowman and Littlefield Press.

Jáuregui, Eduardo (2008). Universalidad y Variabilidad Cultural de la risa y el humor. AIBR: Revista de Antropología Iberoamericana, vol. 3 (1), pp. 46-63. DOI: https://doi. org/10.11156/176 
Kaufman, Gloria, J. y Blakley, Mary Kay (1980). Pulling our own strings: Feminist humor and satire. Bloomington: Indiana University Press.

Kramer, Chris A. (2015). Subversive Humor. Dissertations (2009 -). Paper 424. Disponible en: http://epublications.marquette.edu/dissertations_mu/424

Letsch, Constanze (30 de julio de 2014). Turkish women defy deputy PM with laughter. The Guardian. Disponible en: https://www.theguardian.com/world/2014/jul/30/ turkish-women-defy-deputypm-laughter

Maíz, Ramón (2003). Poder, Legitimidad y Dominación. En Maíz, R.; García, E. y Arteta, A. Teoría Política: Poder, Moral, Democracia (pp. 64-96). Madrid: Alianza Universidad.

Martin, Rod (2008). Psicología del humor: un enfoque integrador. Madrid: Orion ediciones.

Martínez-Palacios, Jone (2017). Participar desde los feminismos. Ausencias, expulsiones y resistencias. Barcelona: Icaria.

—, (2018). No te pongas nerviosa. Navarra: Pamiela.

Méndez, Elena (2013). Discursive mechanisms of informative humor in Spanish media. En Ruiz-Gurillo, Leonor y Alvarado, María Belén (coord.) Irony and Humor. From pragmatics to discourse (pp. 85-106). Amsterdam: John Benjamins.

-, (2014). La parodia informativa como frivolización del discurso político. En Círculo de Lingüística Aplicada a la Comunicación, vol. 59, pp.61-91. DOI: http://dx.doi. org/10.5209/rev_CLAC.2014.v59.46709

Merino, Ana (2001). Women in Comics: a space for Recognizing Other Voices. En The Comic Journal, N. ${ }^{\circ}$ 237, pp. 44-48.

Molina, Paula (21 de junio de 2017). El 'chiste machista' que obligó al expresidente y candidato Sebastián Piñera a pedir perdón. BBC Mundo. Disponible en: http:// www.bbc.com/mundo/noticias-america-latina-40350828

Montes, Rocío (21 de junio de 2017). A Chile no le hace gracia la broma machista de Piñera. El País. Disponible en: https://elpais.com/internacional/2017/06/21/ actualidad/1498010659_748658.html

Moreno, Carmelo (2007). Humor político, entre la terapia y el ridículo. Notas para una teoría política que hable del humor en serio. VIII Congreso Español de Ciencia Política y de la Administración Política para un mundo en cambio. Valencia. 
—, (2015). Reírse de uno y/o reírse de otros. La compleja relación (política) entre el humor étnico y la diversidad social. Versión. Estudios de Comunicación y Política, n. ${ }^{\circ}$ 35, pp. 114-129. Disponible en: http://version.xoc.uam.mx/

Platón (2005). La República. España: Ediciones 74.

Rodríguez, Carmen (2014). Turquía en 2014: elecciones y democratización. Afkar / Ideas, N. ${ }^{\circ} 41$, pp. 38-40.

Rousseau, Jean-Jacques (1985). Emilio o la educación. En Molina, Cristina Dialéctica feminista de la Ilustración (p. 125). Barcelona: Anthropos.

Sartre, Jean-Paul (2016). El ser y la nada. Buenos Aires: Losada.

Scott, James C. (2003). Los dominados y el arte de la resistencia. Mexico: Ediciones Era.

Strzelecka, Ewa K. (2017). Mujeres en la Primavera Árabe: Construcción de una cultura política de resistencia feminista en Yemen. Madrid: Consejo Superior de Investigaciones Científicas (CSIC).

Vasallo, Brigitte (2015). ¿Quién teme a la sátira lesbofeminista? Pikara. (16 de abril). Disponible en: http://www.pikaramagazine.com/2015/04/quien-temea-la-satira-lesbofeminista/

Walker, Nancy (1991). Toward Solidarity: Women's Humor and Group Identity. En Sochen, June (ed.) Women's Comic Visions (pp. 57-84). Detroit: Wayne State University Press.

Young, Iris M. (1989). Polity and Group Difference: A Critique of the Ideal of Universal Citizenship. Ethics, n. ${ }^{\circ} 99$ (2), pp. 250-274. DOI: 10.1086/293065

—, (1990). Justice and the Politics of Difference. Princeton: Princeton University Press. 